\title{
ALGUNS GALICISMOS DE CERTA IMPRENSA PAULISTANA
}

\author{
Italo Caroni
}

As restrições contidas no enunciado acima não escondem nenhuma intenção irônica, procurando apenas circunscrever em seus justos limites o projeto que deu origem ao presente estudo. Leitor assíduo da imprensa quotidiana e professor de francês, sempre fomos sensível à presença de termos ou expressões francesas nas páginas de nossos jornais. Donde a idéia de reunir estes galicismos, para comentá-los em seguida, de modo - se não científico - pelo menos sistemático. Galicismo é tomado aqui em sentido amplo, para designar todo e qualquer vestígio lingüístico francês na linguagem de nossa imprensa.

\section{I-Coleta do material}

O levantamento de dados foi feito ao acaso da leitura habitual de $O$ Estado de São Paulo e do Jornal da Tarde, durante o período de setembro de 1977 a abril de 1979 A escolha das secções do jornal também não obedeceu a nunhuma regra preliminar, sendo que o tratamento quantitativo feito a posteriori revelou a seguinte distribuição temática do total de 82 artigos lidos:

\begin{tabular}{lcr}
\multicolumn{1}{c}{ Matéria } & No de artigos & Porcentagem \\
política & 50 & $60,97 \%$ \\
cinema & 12 & $14,63 \%$ \\
crítica literária & 6 & $7,31 \%$ \\
artes plásticas & 4 & $4,87 \%$ \\
teatro & 3 & $3,65 \%$ \\
moda & 2 & $2,43 \%$ \\
crônlca & 2 & $2,43 \%$ \\
correio do leitor & 1 & $1,21 \%$ \\
televisão & 1 & $1,21 \%$ \\
música & 1 & $1,21 \%$
\end{tabular}


Alguns galicismos .

O corpus acima pode ser reduzido, sem grandes distorções, a duas rubricas fundamentais: política e letras e artes. A política, por sua vez, supera amplamente todas as demais matérias, estabelecendo assim a tonalidade dominante no conjunto dos textos lidos. Vale lembrar ainda que, dos 50 artigos políticos, 24 são assinados e aparecem, quase sempre, no editorial de ambos os periódicos.

\section{II - Tratamento do material}

O material coletado foi repartido em três conjuntos: palavras, grupos de palavras, frases. O fator classificatório ateve-se, tanto quanto possível, ao aspecto externo do empréstimo, o qual surge no texto vernáculo sob a forma de um único vocábulo, de mais de um vocábulo, ou de vários vocábulos que, consolidados por um verbo, constituem um enunciado autônomo.

Para cada conjunto, adotou-se a classificação por ordem alfabética do primeiro termo recenseado, qualquer que seja a sua classe gramatical. Exemplo: "de fond en comble" entra na letra $d$ (e não em $f$, de "fond", nem em $c$, de "comble") Isto porque o critério usual da hierarquia de classes gramaticais (substantivo, verbo, adjetivo, pronome, advérbio etc) nem sempre resolve todas as dificuldades: "aidemémoire", "ancien régime", "hors-concours" deveriam ser registrados, logicamente, em "mémoire", "concours"; no entanto, os dicionários procedem às vezes de modo contrário, colocando o substantivo em segundo plano e iniciando o registro léxico, respectivamente, por um verbo, um adjetivo e um advérbio ou preposição. O procedimento aqui adotado permite ganhar tempo, indo-se procurar o galicismo na ordem alfabética do primeiro sinal gráfico que aparece. Antes de examinarmos os três conjuntos de empréstimos, impõem-se mais alguns esclarecimentos preliminares.

No exame dos dois primeiros conjuntos - palavras e grupos de palavras -, procedemos ao confronto entre os dois idiomas, nos níveis fonético-ortográfico, morfo-sintático e semântico. (Quanto ao terceiro grupo - frases - o tratamento específico será explicitado sob aquela rubrica). Adotamos, para este estudo contrastivo, os seguintes dicionários: Dictionnaire Larousse du Français Contemporain, edição de 1971, e Novo Dicionário Aurélio (6 $6^{\text {a }}$ impressão), 1975 As demais obras utilizadas figuram na bibliografia final.

Os conjuntos de palavras e grupos de palavras são dispostos em três colunas: a primeira, empréstimo, contém a forma francesa inserida na frase portuguesa; a segunda, a forma francesa correta; e a 
terceira, a forma registrada pelo Novo Aurélio. O sinal - indica ausência do termo na coluna. A coluna dos empréstimos consigna o termo tal como foi encontrado - correto ou errado - no texto jornalístico.

\begin{tabular}{|c|c|c|}
\hline empréstimo & forma francesa correta & Novo Aurélio \\
\hline affaire & affaire & affaire \\
\hline affreux & affreux & - \\
\hline atelier & atelier & atelier/ateliê \\
\hline auteur & auteur & - \\
\hline blasé & blasé & blasé \\
\hline bombonriè:-e & bombonnière & bombonnière \\
\hline boulevard & boulevard & bulevar \\
\hline boutade & boutade & boutade \\
\hline boutique & boutique & $\longrightarrow$ \\
\hline capitonnés & capitonnés & $\longrightarrow$ \\
\hline carroussel & carrousel & carrossel \\
\hline chauvinista & chauviniste & chauvinista \\
\hline contestatrices & contestatrices & - \\
\hline couture & couture & - \\
\hline décor & décor & décor \\
\hline démarches & démarches & démarches \\
\hline élan & élan & élan \\
\hline élites & élites & elites \\
\hline enragé & enragé & \\
\hline entourage & entourage & entourage \\
\hline événementielle & événementielle & $\longrightarrow$ \\
\hline fainéants & fainéants & - \\
\hline flambé & flambé & - \\
\hline foyer & foyer & foyer \\
\hline front & front & front \\
\hline gaffe & gaffe & gafe \\
\hline gagá & gaga & gagá \\
\hline gendarme & gendarme & gendarme \\
\hline gourmet & gourmet & gourmet \\
\hline helàs & hélas & hélas \\
\hline
\end{tabular}


empréstimo

lingerie

marchands

marron

melange

milieu

pochade

politesse

portraits

potins

pouff

privée

reussite

reveillon

sachet

visagiste forma francesa correta

Novo Aurélio

lingerie

marchands

marron

mélange

milieu

pochade

politesse

portraits

potins

pouf

privée

réussite

réveillon

sachet

visagiste lingerie

marron

pochade

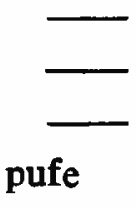

reveillon

sachê

\section{A-Nivel fonético-ortográfico}

O confronto entre as colunas 1 e 2 permite observar que apenas 8, dentre os 45 vocábulos, apresentam discrepâncias ortográficas: "carroussel"/"carrousel" "chauvinista"/"chauviniste", "gaga"/"gagá" "helàs" / "hélas"; "melange" / "mélange"; "pouff" / "pouf" "reussite"; "reveillon"/"reveillon"

- a presença dos dois ss em "ca"roussel" indica, em po:tuguês, a pronúncia da consoante como fricativa surda; ao passo que em francês as duas pronúncias são possiveis: surda ou sonora, fato que se traduz na grafia com um único $s$. Esta ambiguidade fonética do francês explica-se, provavelmente, pela etimologia napolitana da palavra (de "carusielli")

- em "chauvinista", o autor do empréstimo nada mais faz do que aportuguesar a ortografia original: ou naturalizar a "inclusão xenófoba", como diria Henri Gobard. (L'Aliénation Linguistique, p. 75).

- a introdução do acento gráfico em "gagá" se $f_{2} z$ necessária, para evitar a confusão com "gaga"

- a grafia "helàs" por "hélas pode resultar de um descuido; a menos que se tenha tentado reconstruir a acentuação oxítona do francês. 
- a supressão dos acentos em "melange", "reussi.e" e "reveillon" impõe-se, visto que a manutenção dos mesmos desorientaria o falante brasileiro quanto à verdadeira sílaba tônica .

- os dois ff de "douff" dificilmente passariam por um de _cuido tipográfico; ou teria o colunista procurado vestir o termo de uma roup gem mais estrangeira, a fim de evitar uma possível semelhança com a nossa interjeição "puf"?

Os 37 vocábulos restantes são empregados na forma francesa correta, sem adaptação de espécie alguma ao portugues. Esta atitude pressupõe, da parte do jornalista, a certeza de estar-se dirigindo a um público suficientemente competente para ler o francês. Contudo, por que não preferir certas formas já aportuguesadas, como: "ateliêe", "carroussel", "elites", "gafe", "pufe", "sachê"? Por que não aportuguesar ou suprimir certos acentos, e escrever "blasê", "bonbonniere", "decor", "demarches", "elan", "enragê", "flambê", em vez de "blasé", "bonbonniére", "décor", "demarches" "élan", "enragé", "flambé"? Por outro lado, se "boulevard" deu "bulevar", "boutade" poderia transformar-se em "butade" "couture" em "cuture", "élan" em "elã", "gourmet" em "gurmê" etc.

\section{$B-$ Nivel morfo-sintático}

Neste nível, ocorreram apenas 4 divergências que, para melhor compreensão, transcrevemos nos contextos lingüísticos em que aparecem:

— " .na ocasião 'do affaire' Odebrecht."

- "Ao que parece, o presidente e 'sua entourage'.. "

- "O que pode resultar disso é 'uma melange' de interesses elei orais e político-regionais..."

- ". levando-se em conta 'a plasticidade reussite' do solo de..." Resumindo tais ocorrências, teríamos, em forma de gráfico•

\section{empréstimo}

o affaire, s.m.

uma melange, s.f. sua entourage, s.f. reussite, adj.
forma francesa correta
Novo Aurelio
l'affaire, s.f.
É feminino em francês
un mélange, s.m.
son entourage, s.m.
E masculino em francês
réussite, s.f.

Nos casos de mudança de gênero gramatical parece ocorrer uma projeção do uso vernáculo sobre o estrangeiro. "O affaire" se justificaria então por analogia genérica com "o caso", "a entourage" e "a melange" por uma tendência a considerar femininas as palavras francesas terminadas em age (posto que a terminação equivalente em por- 
tuguês, agem, denota feminino: bagagem, garagem, homenagem, personagem, viagem etc)

Em "plasticidade reussite", houve, evidentemente, confusão entre a forma nominal "réussite" e o particípio passado ou adjetivo "réussie" Embora possa haver, em alguns casos, identidade entre o substantivo e a forma participial adjetiva ("la montée" e "elle este montée, "la partie" e "elle est partie", "la sortie" e "elle est sortie" etc.) isto não constitui uma regra. Talvez não se deva excluir, no caso, uma eventual contaminação do italiano, onde "riuscita" aparece com os dois valores.

\section{C-Nível semântico}

Transcrevendo os textos em que ocorrem os empréstimos, assinalamos agora as divergências de significado entre o português e o francês, comentadas uma a uma.

bonbonnière- "Como se já não bastesse o preço do ingresso, que diminui o nosso bolso, ainda temos que aguentar as exploraçôes da "bonbonnière", que cobre até.

(Port.)-bonbonnière- loja onde se vende bombons.

(Fr.) -bonbonnière- estojo artisticamente decorado no qual se colocam bombons. Note-se também que a palavra bombom não designa a mesma coisa nos dois idiomas. "Bombom", que, segundo o Novo Aurélio, é uma "guloseima de confeitaria em geral de chocolate, contendo, às vezes, recheio de frutas, licores" designa algo de muito mais específico que o "bonbon" francês: doce que se chupa ou mastiga (e cuja tradução mais adequada seria "bala") .

boutique "Assim cada vez mais as etiquetas estrangeiras invadem as boutiques, vendendo não só roupas mas também acessórios, malas, bolsas e perfumes.

(Port.)-boutique-(não registrado no Aurélio) refere-se apenas à moda e se emprega para designar o tipo de loja definido no exemplo acima transcrito.

(Fr.) -boutique- muito mais genérico, se relaciona a qualquer 10 cal destinado ao comércio de varejo; e equivale, portanto, à nossa "loja" Nem sempre, contudo. Uma "boutique de parfumerie" no de ser uma "loja de perfumes"; mas, como traduzir a "boutique du boulanger"? No caso do emprego pejorativo, a "boutique" poderia, até por seu aspecto sonoro, associar-se ao "boteco"; mas também aqui, os referentes não se confundem, pois no francês trata-se de 
"loja" de má qualidade, enquanto que português só pode tratar-se de "bar" de segunda categoria.

carrousel "É preciso chamar os homens de idéius e de visão para modificar urgentemente o 'carroussel' que gira lentamente, ameaçando parar."

(Port.)-carrossel-(definição técnica do Novo Aurélio) "Aparelho de feiras, festas e parque de diversões, constituído de um rodízio que sustém uma viga vertical, à qual se prendem hastes horizontais em cujas extremidades estão presos cavalos de madeira, carrinhos ou outras figuras que giram com o eixo."

(Fr.) -carroussel- Eis a definição que consta no Nouveau Petit Larosel Illustré: "Représentation donnée par des groupes de cavaliers faisant evoluer leurs chevax et, par ımage, circulation intense de véhicules en divers sens."

Não se trata, pois, da mesma coisa. O francês possui um termo distinto, para designar o que chamamos de "carrosel" Referimonos ao "manège": "Attraction foraine où des figures d'animaux, des véhicules etc., qui servent de monture à des enfants, sont animés d' un mouvement circulaire" segundo o Larousse Contemporain. (De "manège" = picadeiro onde se amansam cavalos ou se ensina equitação) A derivação semântica explica-se, nos dois casos, pela presença de cavalos que circulam com intensidade. Para o francês, "carroussel" lembra evoluções em diversas direções; "manège" movimentos circulares. Razão pela qual o segundo termo corresponde, melhor do que os torneios de cavalaria, à definição do referido brinquedo dos parques de diversões.

marron "Resume-se a um flash do cotidiano mais negro, a um episódio de imprensa 'marron' narrado com a vivacidade e a autenlarga cobertura a crimes, fatos escabrosos e anomalias sociais"

(Port.) -marron- A propósito da expressão "imprensa marron" o Novo Aurélio explica: "a que explora o sensacionalismo, dando cobertura a crimes, fatos escabrosos e anomalias sociais."

(Fr.) -marron- O Larousse Contemporain diz: "qui exerce une profession d' une façon irrégulière, en se livrant è des pratiques illégales. Un médecin marron."

Já aqui também derivação de sentido. "Imprensa marron", seria uma imprensa desqualificada, mas não juridicamente, como na acepção francesa. 
A comparação entre as colunas 1 e 3 revela que, das 45 palavras, o Novo Aurélio regitra 26, das quais 9 com adaptação foneticoortográfica e 17 na forma francesa original. Para este mesmo conjunto de 45 palavras, o Dicionário de Galicismos, de Carlos Góias, contém as 11 seguintes: "atelier" "blasé", "bonbonnière" "boulevard", "carrocel", "chauvinista", "elite", "entourage", "gendarme", "pochad", "sachet" Destas 11, "atelier" e "gendarme" constam sem equivalentes em português. Quanto às 9 restantes, Carlos Gois propõe as seguintes substituições: "enervado" por "blasé", "confeitaria" por "bonbonnière", "alameda" por "boulevard", "rodízio" por "carrocel", "xenófobo" por "chauvinista", "escol" por "elite", "círculo" por "entourage", "farça" por "pochade" (galicismo que teria sofrido um desvio semântico quanto à noção originária de "esboço ligeiro"), "saquete" por "sachet"

\section{GRUPOS DE PALAVRAS}

empréstimo
aide-mémoire
ancien-régime
beau-frère
bijoux-sachets
de fond en comble
dejà vu
enfant terrible
entente cordiale
et pour cause
faux pas
force de frappé
génie du chef
grèves perlées
hors concours
la chienlit
laissez faire
mal à l'aise
metteur en scène
par droit de naissance
pot- pourri
prêt-à-porter
tour de force
tout court
vis-a-vis
vol doiseau

\begin{tabular}{|c|c|}
\hline \multirow{3}{*}{$\begin{array}{l}\text { forma francesa correta } \\
\text { aide-mémoire } \\
\text { Ancien Régime } \\
\text { beau-frère }\end{array}$} & Novo Aurélio \\
\hline & aide-mémoire \\
\hline & Ancien Régime \\
\hline $\begin{array}{l}\text { de fond en comble } \\
\text { déjà vu }\end{array}$ & - \\
\hline enfant terrible & enfant terrible \\
\hline $\begin{array}{l}\text { Entente Cordiale } \\
\text { et pour cause } \\
\text { faux pas } \\
\text { force de frappe }\end{array}$ & Entente Cordiale \\
\hline grèves perlées & $\longrightarrow$ \\
\hline hors concours & hors-concours \\
\hline la chienlit & $\longrightarrow$ \\
\hline laissez faire & laissez-faire \\
\hline malaise & \\
\hline metteur en scène & $\bar{r}$ \\
\hline pot-pourri & pot-pourri \\
\hline prêt-à-porter & prêt-à-porter \\
\hline tour de force & tour de force \\
\hline tout court & tout court \\
\hline vis-à-vis & vis-à-vis \\
\hline
\end{tabular}

vol d'oiseau 


\section{A-Nível fonético-ortográfico}

As discrepâncias entre as colunas 1 e 2 são, por assim dizer, insignificantes:
acento: "dejà vu" por "dejá vu", "force de frappé" por force de frappe", "a-vis' 'por "vis-à-vis."
apóstrofo: "vol doiseau" por "vol d'oiseau"
maiúscula/minúscula: "ancien régime" por "Ancien Régime", en- tente cordiale" por "Entente cordiale"
traço de união: "hors-concours" por "hors concours", "laissez-faire": por "laissez faire."

A presença ou ausência de acentos em "dejà vu" e "vis-a-vis" nada significa, foneticamente, para os falantes que desconhecem o idioma francês. Quanto aos iniciados, aos quais se dirige inconscientemente o articulista, o erro gráfico é logo notado. O mesmo acontece com o acento indevido de "force de frappé" e com a ausência do apóstrofo em "vol doiseau"

As minúsculas de "ancien régime" e "entente cordiale" explicam-se pela generalização de fatos históricos que, na origem, são únicos Empregadas fora do contexto em que se produziram, estas duas expressões perdem sua característica de nomes próprios.

Se o Novo Aurélio incorre no equívoco de introduzir o traço de união em "hors-concours" e "laissez", não há por que critícá-lo. As regras ortográficas nem sempre conseguem obediência unânime: o Nouveau Petit Larousse escreve "hors-concours"; o Larousse Contemporain, "hors concours"

\section{$B-N$ îxel morfo-sintático}

Apenas duas observações a fazer. No verbete "aide mémoire", o Novo Aurélio, após ter definido o galicismo, acrescenta: "( $\mathrm{pl}$. aidemémoires)"; o Larousse Contemporain, porém, registra o termo como substantivo invariável. O jornalista que utilizou "mal à "I'aise' errou quanto à categoria gramatical e ao gênero, ao dizer: " $E$ isto gera uma certa 'mal à l'aise' em Havana." Na realidade, queria dizer "malaise" que, além de tudo, é substantivo masculino e não feminino. (Porque não dizer logo "um certo mal-estar"? Evitar-se-ia o erro e o ridículo)

\section{C-Nível semântico}

No plano semântico, não houve contra-sensos. A boa compreensão exige do leitor não apenas competência linguística mas também 
razoável familiaridade com certos fatos da história francesa, recente ou passada. Algumas observações se fazem, contudo, necessárias.

Cinco dos grupos de palavras recenseados não aparecem no $L a$ rousse Contemporain: "bijoux-sachets", "force de frappe", "génie du chef", "par droit de naissance" e "la chienlit"

- bijoux-sachets- neologismo que o colunista mundano fabricou Para uso próprio e que, portanto, seria inútil procurar em dicionários franceses: "Abandonou definitivamente olhos e bocas como assunto e, talvez inspirada pelos demônios de $O$ bebe de Rosemary, resolveu fazer jóias aromáticas. Como esses 'bijoux-sachets' serão exibidos na loja.

- force de frappe- Aparece num paralelo entre duas personalidades políticas: "O general Geisel tem até o Acoido Nuclear com a Alemanha a lembrar, remotamente, a 'force de frappé' do general De Gaulle" Alusão ao controvertido projeto com que De Gaulle, quando de seu retorno ao poder, pretendia dotar a França de uma força de dissuação moderna suficientemente eficaz para garantir-lhe independência com relação aos blocos políticos hegemônicos. A definição técnica detalhada deste projeto político-militar vem explanada nas enciclopédias mais recentes como, por exemplo, o Grand Larousse Encyclopédique.

- génie du chef- Ocorre na caracterização da mesma personalidade do texto supra-citado: "Para homem formado na escola da guerra, é como se o 'génie du chef', que decide sem dúvida as batalhas, fosse suficiente para superar a relação objetiva de forças, sendo tão só suficiente para, enunciada a vontade, fazer-se a luz e obter-se a vitória." Os dicionários consultados não permitiram rastrear a origem da expressão, que nenhum deles registra, aliás, tal qual. Pelo contexto, percebe-se uma nitida referência aos monarcas absolutos do Antigo Regime fracês, os quais, contemplados com um poder de origem divina, planavam acima dos simples mortais.

- par droit de naissance- (Ou, "par le droit de naissance"?) Expressão que também não conseguimos localizar, nas obras de referência consultada. É utilizada para definir um de nossos recém falecidos partidos políticos: "Nosso chamado partido da oposiçāo pertence, sem dúvida possível ('par droit de naissance'), a essa categoria." 
- la chienlit- Consta, no Larousse Contemporain, como sinônimo de "mascarade", que, por sua vez, assim se define: "mise en scène trompeuse, hypocrite". Mas o termo tem sentido histórico. No prosseguimento do paralelo em que aparece "force de frappe" "la chienlit" (cuja tradução aproximativa e atenuada poderia ser, por exemplo, "a palhaçada") evoca a expressão altaneira, depreciativa e um tanto antiquada com que De Gaulle classificou os acontecimentos políticos de maio de 1968 em Paris.

Comparando as colunas 1 e 3 , constata-se que mais da metade dos empréstimos não figuram no Novo Aurélio: "beau-frère", "bijoux-sachets", de fond en comble", "déjà vu", et pour cause", "faux pas", "force de frappe", "génie du chef", "grèves perlées", "la chienlit", "malaise", "metteur en scène", "par droit de naissance", "vol d'oiseau" Quanto a esta lista, seria possível:

- substituir simplesmente pela respectiva tradução: "beau-frère" = "cunhado", "bijoux-sachets" = "jóia aromática" "faux pas" = "passo em falso", "malaise" = "mal-estar", "metteur en scène = "diretor", "à vol d'oiseau" = "a vôo de pássaro" (registrada no Novo Aurélio)

- manter em francês, por se referirem a fatos históricos e de civilização: "force de frappe", "grèves perlées" "la chienlit" e, possivelmente, "génie du chef" e"par droit de naissance"

Restariam "de fond en comble", "déjà vu", "et pour cause" A primeira destas expressões teria um equivalente adequado em "de cabo a rabo"; mas esta última ainda não se usa, entre nós, sem alguma reticência. As outras duas, também dificilmente adaptáveis em vernáculo, talvez venham a se incorporar ao nosso léxico, como as seguintes, já incluídas no Novo $A u^{r}$ ćlio: "hors concours", "tour de force", "tout court" e "vis-à-vis"

\section{F R A S E S}

Neste último conjunto de galicismos, o levantamento forneceu a seguinte relação de frases, históricas ou não, utilizadas seja como título de artigos, seja como parte integrante do texto:

\footnotetext{
- "C'est la nuit qu'il est beau de croire à la lumière"

- "C' est mon opinion et je la partage"

- "je ne sais pas"

- "le chevalier sans peur et sans reproche"

- "L'Etat c'est moi"

— "Les jeux sont faits"
} 
- "L' Intendance suit"

- Plus ça change, plus c' est la même chose"

— "Qui se ressemble s'assemble"

- "Qui veut faire l'ange fait la bête"

Pela sua própria natureza, estes empréstimos não figuram, normalmente, num dicionário comum. Seu emprego se verifica, sobretudo, em editoriais assinados por pessoas cultas, dotadas de um bem fundamentado conhecimento do material lingũístico e da cultura francesa. Via de regra, aliás, estes autores assinalam as fontes dos empréstimos e não cometem erros em sua utilização. Não há, portanto. como se proceder ao exame contrastivo francês/português. Note-se apenas, a título de curiosidade, que o Novo Aurélio registra a expressão "sans peur et sans reproche" (com "reproche" grafado inadvertidamente "repróche") e que o $O$ Pequeno Dicionário Brasileiro au Língua Portuguesa inclui, em seu apêndice "Palavras e expressões estrangeiras frequentemente usadas", a célebre frase "L'Etat c'est moi"

Completando este ítem, passamos a fornecer as referências, que permitem melhor compreender e situar cada frase. Para isto muito contribuiram as pistas fornecidas pelos próprios articulistas e que foram confirmadas ou completadas através da consulta de obras especializadas, como dicionário de citações e de provérbios.

- C'est la nuit qu'il est beau de croire à la lumière". Edmond Rostand, Chantecler.

- C'est mon opinion et je la partage". É uma, entre muitas outras, das sandices memoráveis que Henri Monnier atribui a seu personagem, Josep Prud'homme, protótipo do burguês, em Mémoires de Joseph Prud'homme, 1857.

- "Je ne sais pas". Extraído de uma simples nota politica, na qual o jornalista constrói a frase francesa, não havendo desta forma nenhuma alusão histórica.

- "Le chevalier sans peur et sans reproche". Assim era cognominado, pelos cronistas da época, Pierle Bayard (1476-1524), herói francês das guerras com a Itália .

— "L'Etat c'est moi". Palavras que Luís XIV teria dirigido ao Conselho de Minigiros em 1661. Entretanto, a atribuição é realmente duvidosa, como o demonstra, por exemplo, 0 . Guerlac, em les Citations françaises.

- "Les jeux sont faits". Frase ritual, com a qual o crupiê encerra as apostas, no jogo da roleta. E que não deixa de evocar o histórico "Alea jacta est", de Cesar. 
- "L'Intendance suit". Frase que o jornalista empresta a De Gaulle, que a pronunciava quando queria manifestar a pouca importância que dava aos problemas ecônomicos. As fontes consultadas não nos permitiram confirmar esta atribuição.

— "Plus ça change, plus c"est la même chose". Alphonse Karr, Les Guêpes e "Voyage autour de mon jardin"

- "Qui se ressemble s'assemble". Conhecido ditado francês que, curiosamente, nenhum dos dicionários de provérbios por nós consultados registrou. Vale lembrar que o autor do empréstimo faz uma interessante sugestão, ao propor como seu equivalente português, a velha expressão "Lé com lé, cré com cré." Também se poderia recorrer ao mais atual "Diz-me com quem andas e te direi quem és."

- “Qui veut faire l'ange fait la bête". Pascal, Pensées, fıag. 257, Ed. Louis Lafuma, Paris J. Delmas et Cie., p. 173: "L'homme n' est ni ange ni bête, et le malheur veut que qui veut faire l'ange fait la bête."

\section{III - $\bar{A}$ guisa de conclusão}

Os dados expostos e examinados levam a algumas constatações que merecem destaque. $O$ francês fornece considerável subsídio ao português, no âmbito das letras e ciências humanas, sobretudo na linguagem política. A freqũência no emprego de galicismos autênticos, correto nos diferentes níveis da análise lingüística, implica, tanto no jornalista quanto no leitor, um bom conhecimento do idioma francês. Fato muito mais notório quando se considera, em particular, a ocorrência de frases profundamente enraizadas numa tradição cultural francesa, que funciona como apreciável fonte de referência. Imprensa elitista e público letrado constituem assim os dois vetores da comunicação. Outra seria a lìnguagem, caso o objetivo fosse falar à massa . Mais da metade dos galicismos levantados nesta pesquisa não estão consignados num dicionário tão recente quanto o Novo Aurélio, e nem mesmo no já mais idoso Dicionário de Galicismos, de Carlos Gois . Donde se pode inferir a vitalidade atual dos galicismos, que não se limitam a um elenco fossilizado em algumas obras de consulta, mas que continuam se renovando.

Seriam estas constestações motivo suficiente para se lançar um brado de alerta? Estaria o português sob ameaça de "etnocídio cultural", como diz Henri Gobard a respeito do francês face ao imperialismo do "anglo-americano"? Se riscos houver, não será certamente 
por causa do francês. Basta ler nossa imprensa diária ou semanal, ouvir o rádio ou ligar a televisão, para se saber qual a língua estrangeira que está penetrando no nosso espaço cultural.

A influência estrangeira é um problema complexo e, quase sempre, passional. É por demais conhecida, no caso da França, a batalha homérica travada por René Etiemble contra o famigerado "franglais"; nos dias atuais, um novo herói, Henri Gobard, sai à liça brandindo a lança nacional contra o invasor estrangeiro, agora batizado "angloamericain" e que conta também com a cumplicidade dos "galio-ricains" As próprias autoridades já tomaram consciência do problema e elaboraram, nestes últimos quinze anos, uma reforçada política de dirigismo lingüístico. Diversos organismos e comissões técnicas foram instituídas, para a defesa da língua francesa: Haut Comité de la Langue Fraçaise, Secrétariat Permanent du Langage de l'Audiovisuel, Association Fraçaise de Terminologie e numerosas comissões ministeriais de terminologia.

Medidas que ajudarão, sem dúvida alguma, a restabelecer um pouco a ordem na casa, mas que não conseguirão, por certo, impedir a entrada de todo e qualquer estrangeirismo. Muitos termos estrangeiros são inevitáveis e insubstituíveis: o máximo que se pode fazer é trajá-los à maneira nacional. Outros são inúteis e, se não caírem por si mesmos, talvez possam ser expelidos por medidas protecionistas. Estaria também o Brasil voltando a atenção para o problema? Segundo notícias recentes, um dos artigos do anteprojeto que vai criar o Conselho Nacional de Propaganda estabelece, para a linguagem do anúncio, o emprego obrigatório do "vernáculo gramaticalmente correto, excluindo o uso de gíria e de palavras e expressões estrangeiras, salvo quando necessárias para transmitir a informação ou o clima pretendido. ( $O$ Estado de São Paulo, 2-12-1979) Entretanto, o editorialista não esconde sua desconfiança quanto aos reais objetivos do projeto, embora elogie a intenção daqueles que pretendem corrigir "as distorções do idioma a que chegamos depois de longo processo de abastardamento cultural"

\section{BIBLIOGRAFIA}

Buarque de Holanda Ferreira A. Novo Dicionário da Língua Portuguesa. 1a ed., 6a impressão, Rio de Janeiro, Editora Nova Fronteira, 1975.

Buarque de Holanda Ferreira, A. Pequeno Dicionário Brasileiro da Língua Portuguêsa. $11^{\text {ạ }}$ ed., Rio de Janeiro, Editora Civilização Brasileira, 1968.

Dictionnaire Larousse du Français Contemporain. Paris, Larousse, 1971. 
R. Etiemble, Parlez-vous franglais? . Paris, Gallimard, "Collection Idées", 1964

E. Genest, Dictionnaire des Citations Françaises. Paris, F. Nathan, 1967

H. Gobard, L'Aliénation Linguistique. Paris, Flammarion, 1976.

O. Guerlac, Les Citations Françaises. Paris, A. Colin, 1933.

Grand Larousse Encyclopédique. 10t, Paris, Larousse, 1960/1964.

Nouveau Petit Larousse Illustré. 131e. édition, Paris, Larousse, s/d.

M. Rat, Dictionnaire des Locutions Françaises. Paris, Larousse, 1957 